\title{
Implementasi Manajemen Lean di Unit Farmasi Rumah Sakit Islam Surabaya A. Yani
}

\author{
Budhi Setianto*, Agus Aan Adriansyah*, Akas Yekti Pulih Asih* \\ *Program Studi Kesehatan Masyarakat, Fakultas Kesehatan, Universitas Nahdlatul Ulama Surabaya \\ Email: budhisetianto@yahoo.com; aan.naufal87@unusa.ac.id; akasyekti@unusa.ac.id
}

\section{ABSTRACT}

Recently, the difference between operating costs and revenue at RSI Surabaya A. Yani was only $15 \%-17 \%$, while the policy wants the difference to reach $30 \%$. Efficiency was needed in various sources of financing, one of which was in the pharmaceutical unit. One method of improving the service efficiency process was lean management. The research objective was to implement lean management in the pharmacy unit of Surabaya Islamic Hospital A. Yani. This was an observational study with an experimental approach through 2 stages. The first stage was to identify problems, and the second stage was to implement lean management per pharmaceutical service stage, namely planning, procurement and purchasing, storage, preparation and distribution and return. Furthermore, compile the results of monitoring and evaluation of lean management and quantitatively and qualitatively measure the results of implementation of lean management. The results of implementation of lean management in the pharmacy unit of Surabaya A Yani Islamic Hospital, which can be carried out from the planning, procurement and purchasing, storage, preparation and distribution and restoration stages. The advice given was the implementation of lean management can be carried out on an ongoing basis and applied in other units and followed by improvement of SIMRS, monitoring the implementation of supply planning, increasing the role of management in contract drafting, evaluating cooperation, , conducting in-depth and continuous communication, increasing the role of the Medical Committee in evaluating and improving the quality of clinical pathways and motivating staff in implementing the Dose Dispensing Unit distribution method.

Keywords: lean management, hospital, pharmacy unit

\section{PENDAHULUAN}

Era JKN telah menjadi suatu peluang dan tantangan untuk rumah sakit dalam meningkatkan kualitas pelayanan. Rumah sakit harus menciptakan dan mengelola suatu sistem agar pelayanan yang diberikan kepada pasien menjadi efektif. ${ }^{1}$ Kendali biaya dan efisiensi tidak hanya dilakukan terhadap costyang digunakan secara langsung untuk perawatan tiap pasien, tetapi juga pembiayaan pada suatu unit kerja. Walaupun demikian, pengelolan rumah sakit untuk menjamin mutu pelayanan yang diberikan kepada pasien harus tetap berpegang pada Standar Pelayanan Minimal yang dibuat pemerintah. $^{2}$ 
Sebagai rumah sakit yang berdiri sejak 1975, RSI Surabaya A. Yani terus berkembang dalam melayani kesehatan masyarakat Surabaya. Berbagai upaya terus dilakukan mengikuti perkembangan teknologi dan peraturan pemerintah yang sering berubah-ubah. Dampak era uncertainty ini membuat rumah sakit harus cepat dalam mengambil keputusan dan melakukan efisiensi diberbagai sumber pembiayaan. Saat ini selisih biaya operasional dengan pendapatan di RSI Surabaya A. Yani hanya 15\%-17\%, sedangkan kebijakan direksi menginginkan selisih tersebut bisa menjadi $30 \%$. Untuk mewujudkan hal tersebut, efisiensi harus dilakukan diberbagai sumber pembiayaan, salah satunya di unit farmasi.

Salah satu Standar Pelayanan Minimal (SPM) dari Kementerian Kesehatan di Unit Farmasi adalah tentang respon time penyiapan obat jadi yakni kurang dari 30 menit. $^{3}$ Di Unit Farmasi RS Islam Surabaya A. Yani rerata waktu tunggu pada Mei, Juni dan Juli 2019 berturut-turut adalah 38,57 menit, 42,28 menit dan 43,79 menit. Data tersebut menunjukkan bahwa RS Islam Surabaya A. Yani belum memenuhi SPM dari Kementerian Kesehatan yang berarti ada ketidakefisienan dalam pelayanan.

Salah satu metode untuk memperbaiki proses pelayanan agar efisien adalah manajemen lean. Saat ini penerapan lean dalam bidang kesehatan banyak berkembang. Lean adalah sebuah alat, sistem manajemen dan filosofi yang merubah suatu rumah sakit menjadi lebih terorganisir dan teratur yang memungkinkan rumah sakit untuk meningkatkan kualitas pelayanan terhadap pasien dengan cara mengurangi kesalahan, waktu tunggu dan efisiensi biaya. ${ }^{4}$

Berdasar data dan fakta tersebut diatas perlu adanya upaya dalam implemen-tasi manajemen lean di Unit Farmasi RS Islam Surabaya A. Yani. Secara umum tujuan dari penelitian ini adalah melakukan implementasi manajemen lean di unit farmasi RS Islam Surabaya A. Yani.
Sedangkan tujuan khususnya adalah melakukan implementasi manajemen lean di unit farmasi RS Islam Surabaya A. Yani per tahap pelayanan farmasi yakni, perencanaan, pengadaan dan pembelian, penyimpanan, penyiapan dan distribusi dan pengembalian.

\section{METODE PENELITIAN}

Penelitian dilakukan di Farmasi RS Islam Surabaya A. Yani, dengan sumber informasi melibatkan para apoteker dan tenaga kefarmasian yang dilakukan dalam dua tahap tahap pertama pada bulan Juli 2019 dan tahap kedua dilakukan pada bulan November 2019. Desain peneltiian adalah studi observasional dengan pendekatan Preexiperimental. Pada tahap pertama dilakukan identifikasi masalah dengan cara berturut-turut yaitu (1) mengidentifikasi alur pelayanan farmasi, (2) melakukan wawancara dengan pemberi pelayanan, (3) menyusun sub kegiatan per tahap pelayanan, (4) melakukan focus group discussion, (5) mengidentifikasi dan menganalisa waste dengan current value stream mapping, (6) memprioritaskan masalah dengan USG, (7) menentukan akar masalah dengan diagram Ishikawa, (8) memprioritaskan akar masalah dengan CARL, (9) menyusun rekomendasi per tahap pelayanan dan (10) menyusun rencana tindak lanjut implementasi.

Selanjutnya dilakukan analisis waste dengan current value stream mapping ${ }^{5}$. Pada bagian ini semua waste dari setiap alur pelayanan farmasi diperingkat dengan metode USG. ${ }^{6}$ Setiap waste akan dinilai dari tiap unsur urgency, strengthness, dan growth dan diberi skor 1-5. Kemudian dilakukan perkalian dari setiap nilai unsur tersebut untuk menghasilan skor total USG dari setiap waste. Waste dengan skor tertinggi akan dipilih untuk dicari akar masalahnya. $^{7}$

Dari masalah terpilih kemudian dicari akar masalah dengan diagram Ishikawa yang terbatas pada aspek man, method dan material. Kemudian diperingkat lagi 
menggunakan metode CARL. Secara teknis sama dengan metode USG hanya pada CARL penilaian menggunakan angka 1-10. Setelah itu disusun rekomen-dasi per tahap pelayanan dan rencana tindak lanjut implementasi. Tahap identifikasi ini berlangsung selama 2 minggu.

Pada tahap kedua dilakukan implementasi pada setiap tahap pelayanan farmasi. Dari 5 tahap pelayanan dipilih 2 tahap yang paling memungkinkan untuk diberi intervensi dalam jangka waktu 3 minggu dan bisa memberikan perbedaan secara kuantitatif. Dua tahap tersebut adalah tahap perencanaan dan tahap penyiapan. Sisanya yakni pengadaan dan pembelian, penyimpanan serta distribusi dan pengembalian sebatas pembuatan SPO. Tahap implementasi ini berlangsung selama 3 minggu. Sedangkan pada periode kedua dilakukan implementasi manajemen lean per tahap pelayanan farmasi yakni perencanaan, pengadaan dan pembelian, penyimpanan, penyiapan dan distribusi dan pengembalian. Selanjutnya menyusun hasil monitoring dan evaluasi implementasi manajeman lean serta mengukur secara kuantitatif dan kualitatif hasil implementasi manajeman lean per tahap pelayanan.

\section{HASIL DAN PEMBAHASAN}

\section{Implementasi Manajemen Lean Tahap Perencanaan}

Pengelolaan sediaan farmasi, alat kesehatan dan bahan medis habis pakai di RSI Surabaya A. Yani dilaksanakan secara multidisiplin, terkoordinir namun belum menggunakan proses yang efektif untuk menjamin kendali mutu dan kendali biaya. ${ }^{5}$ Apoteker bertanggung jawab terhadap pengelolaan sediaan farmasi, alat kesehatan, dan bahan medis habis pakai yang menjamin seluruh rangkaian kegiatan sesuai dengan ketentuan yang berlaku serta memastikan kualitas, manfaat dan keamanannya. ${ }^{6} \quad$ Pengelolaan sediaan farmasi, alat kesehatan, dan bahan medis habis pakai di RSI Surabaya A Yani merupakan suatu siklus kegiatan dimulai dari tahap perencanaan, pengadaan dan pembelian, penyimpanan, penyiapan dan distribusi dan pengembalian.

Pada tahap perencanaan ditemukan waste kategori defectyaitu pengumpulan data obat masih manual, belum dilaksanakan langkah perencanaan dan belum memaksimalkan kontrak dalam pemilihan supplier. Dengan metode USG didapatkan masalah yang menjadi prioritas adalah belum dilaksanakan langkah perencanaan. Dari prioritas masalah tersebut dicari beberapa akar masalahnya dengan diagram Ishikawadan diperingkat dengan metode CARL. Hasilnya, akar masalah yang prioritas adalah belum adanya staf ahli yang mampu menyusun perencanaan. Sehingga rekomendasi penyelesaiannya dilakukan dengan cara yaitu melatih staf perencanan perbekalan farmasi mengenai metode pengadaan terpilih dan menerapkannya. ${ }^{8}$

Implementasi manajemen lean yang dilakukan secara berturut turut adalah pelatihan perencanaan perbekalan kepada staf farmasi, penyusunan kategorisasi perbekalan (Pareto) dan penetapan nilai stok perbekalan (MMSL) dan uji coba program dan format perbekalan baru selama 1 bulan dan sinkronisasi dengan program SIMRS. Hasilnya adalah (1) perencanaan dilakukan berdasar data yang ada di excel berupa jumlah obat yang harus dibeli disertai dengan harga obat tersebut. (2) insiden obat kosong berkurang dan gudang bisa menyimpan obat lebih efesien berdasar kebutuhan dan pemakain di pelayanan, (3) biaya pembelian obat selama penelitian sebesar turun sebesar $20,34 \%$ per minggu dan (4) biaya rerata pembelian obat cito sesudah metode perencanaan yang baru turun sebesar $44,96 \%$ per minggu.

Selama pelaksanaan implementasi didapatkan evaluasi sebagai berikut. Pertama, proses perencanaa masih manual dengan menggunakan excel sehingga belum terotomatisasi. Selanjutnya, fluktuasi pemakaian obat tertentu yang 
termasuk kategori $\mathrm{C}$ dikarenakan obat tersebut dipakai untuk pasien privat sedangkan jumlah pasien privat rendah. Terakhir, ketebatasan gudang yang menyebabkan cairan dasar tidak dapat dimasukkan dalam rumus MMSL karena bila dipaksakan order sesuai stok maksimal maka gudang tidak cukup untuk menampung jumlah sesuai stok maksimal.

\section{Implementasi Manajemen Lean Tahap Pengadaan dan Pembelian}

Pada tahap pengadaan dan pembelian ditemukan waste beberapa kategori diantaranya tidak ada dokumen resmi purchase order saat pemesanan ke distributor (defect), waktu kedatangan tidak sesuai jadwal (motion) dan input barang datang tidah real time(defect). Dengan metode USG didapatkan masalah yang menjadi prioritas adalah tidak ada dokumen resmi purchase order saat pemesanan ke distributor. Dari prioritas masalah tersebut dicari beberpa akar masalahnya dengan diagram Ishikawa dan diperingkat dengan metode CARL. Hasilnya, akar masalah yang prioritas adalah purchase order dilakukan melalui telepon tanpa dokumen resmi saat pemesanan. Sehingga rekomendasi penyelesaiannya dilakukan dengan cara yaitu memaksimalkan dokumen purchase order. ${ }^{8}$

Implementasi manajemen lean yang dilakukan secara berturut turut adalah pembuatan dokumen resmi purchase order saat awal pemesanan, komunikasi mengenai purchase order bisa dilakukan melalui email dengan konfirmasi melalui telepon dan penerimaan barang harus dicocokkan dengan purchase order. Pada tahap ini implementasi tidak bisa dilakukan secara maksimal dikarenakan melibatkan pihak perusahaan farmasi sehingga membutuhkan waktu yang lebih lama. Namun demikian bila rekomendasi dijalankan harapannya adalah (1) obat diantar sesuai dengan apa yang tertulis dalam purchase order yang dikirim melalui email dan (2) dengan adanya sistem punishment bahwa obat yang dibayar sesuai dengan purchase order maka obat yang dikirim akan sesuai dengan faktur.

Selama pelaksanaan implementasi selama dua minggu didapatkan evaluasi bahwa SIMRS rumah sakit seharusnya bisa memfasilitasi pembuatan purchase order secara elektronik dengan mengambil data dari perencanaan, sehingga alur pelayanan pada tahap pengadaan dan penerimaan dapat dilakukan lebih efisien.

\section{Implementasi Manajemen Lean Tahap Penyimpanan}

Pada tahap penyimpananditemukan empat waste yaitu identifikasi kebutuhan depo atau gudang tidak digunakan sebagai bahan perencanaan pengadaan (defect), belum adanya labeling dan penataan menggunakan warna atau alfabet(inventory), penggunaan SIM Logistik kurang optimal dalam memfasilitasi (non-utilized talent) dan input dalam SIMRS dilakukan dua kali (extra processing). ${ }^{9}$ Dengan metode USG didapatkan masalah yang menjadi prioritas adalah identifikasi kebutuhan depo atau gudang tidak digunakan sebagai bahan perencanaan pengadaan. Dari prioritas masalah tersebut dicari beberapa akar masalahnya dengan diagram Ishikawa dan diperingkat dengan metode CARL. Hasilnya, akar masalah yang prioritas adalah belum ada sistem kontrol dalam hal penyimpanan di depo dan gudang. Sehingga rekomendasi penyelesaiannya dilakukan dengan cara yaitu menata ulang sistem monitoring dan evaluasi di gudang dan depo.

Implementasi manajemen lean yang dilakukan secara berturut turut adalah menyusun prosedur dan lakukan sosialisasi, uji coba prosedur baru dan lakukan supervisi secara intensif dan melakukan evaluasi kinerja secara berkala dengan unit terkait. ${ }^{10}$ Pada tahap ini implementasi hanya sebatas pembuatan SPO baru mengenai penyimpanan obat dan alat kesehatan. Hal ini dikarenakan 
penyusu-nan kebijakan yang memerlukan pertemu-an berkala dengan jajaran pelayanan sementara waktu penelitian yang terbatas membuat implementasi tidak bisa dilakukan dengan intervensi. Namun demikian bila SOP baru dijalankan harapannya adalah (1) obat yang disimpan di depo bisa diminimalisasi dan stok tidak meluber dan (2) meningkatnya kepatuhan pelabelan stok.

Penyelesaian masalah di tahap penyimpanan harus dimulai dari perbaikan SDM dan monitoring prosedur di gudang farmasi RSIA A Yani Surabaya. Diperlukan penataan ulang dan monitoring pelaksanaan penyimpanan perbekalan farmasi sesuai standar dan prosedur yang telah disepakati oleh rumah sakit. Dengan harapan tidak terjadi kesalahan peletakan obat dan alat kesehatan sesuai rak dan tempat penyimpanan berdasarkan label penyimpanan. Metode FIFO (First In First Out) dan FEFO (First Expired First Out) juga harus dijalankan. Dengan adanya monitoring berkala dan intens pada proses ini maka risiko dapat dikendalikan dan kinerja unit menjadi lebih efektif dan efisien.

\section{Implementasi Manajemen Lean Tahap Penyiapan}

Pada tahap penyiapan ditemukan empat kategori waste diantaranya yaitu pengerjaan obat menjadi lebih lama (waiting), duplikasi proses ketika penghitungan biaya (extra processing), boros pada pemakain kertas dan ATK (inventory) dan SIMRS belum memfa-silitasi waktu telaah obat (motion). Dengan metode USG didapatkan masalah yang menjadi prioritas adalah boros pada pemakain kertas dan ATK. Dari prioritas masalah tersebut dicari beberpa akar masalahnya dengan diagram Ishikawa dan diperingkat dengan metode CARL. Hasilnya, akar masalah yang prioritas adalah SIMRS belum mendukung stok otomatis dan terintegrasi dengan stok resep. Sehingga rekomendasi penyelesaiannya dilakukan dengan cara yaitu optimalisasi penggunaan resep elektronik dan meniadakan resep fisik di poli.

Implementasi manajemen lean yang dilakukan secara berturut turut adalah membicarakan rencana kerja untuk mendapat dukungan dari manajemen (edaran direktur), memilih poli yang bisa mendukung penggunakan resep elektronik, berkoordinasi dengan kepala poli dan berkomunikasi dengan dokter spesialis mengenai rencana peniadan resep fisik serta penggunaan resep elektronik sepenuh-nya. Pada implementasi ini dipilih poli obgyn yang relatif memiliki jenis obat yang sama dan jarang berbentuk racikan. Hasilnya adalah (1) TTK cukup lihat di resep elektronik dalam bentuk cetakan (nama obat tertulis jelas), (2) perawat tidak perlu melakukan hal tersebut karena tidak diperbolehkan dan berpotensi tertukarnya resep, (3) tidak perlu menggunakan layanan antar obat karena waktu tunggu cepat sehingga pasien mendapat edukasi apoteker dan (4) waktu tunggu obat jadi kurang dari 5 menit dimana standar waktu tunggu obat jadi maksimal sebesar 30 menit. ${ }^{11,15}$

Selama pelaksanaan implementasi didapatkan kendala yakni template resep elektronik yang belum sesuai harapan rumah sakit (verifikasi apoteker dan menu racikan) dan jarak yang cukup jauh antara TTK di bagian penerimaan resep dan bagian penyiapan sehingga malah menambah waste (motion).

\section{Implementasi Manajemen Lean Tahap Distribusi dan Pengembalian}

Pada tahap distribusi dan pengembalian ditemukan empat kategori waste diantaranya yaitu adanya duplikasi pekerjaan apoteker (extra processing), penggunaan petugas farmasi dalam mengantarkan obat (non utilized talent), terjadi proses pengecekan ulang dan perlengkapan obat yang seharusnya dilakukan ketika pemesanan obat (defect), Obat yang tidak terpakai harus dikembalikan ke Farmasi (motion) dan risiko didapatkan obat yang tidak 
dikembalikan (invent-tory). ${ }^{11,20}$ Dengan metode USG didapatkan masalah yang menjadi prioritas adalah terjadi proses pengecekan ulang dan pelengkapan obat yang seharusnya dilakukan ketika pemesanan obat karena SIMRS belum mendukung stok otomatis dan terintegrasi dengan stok resep. ${ }^{12,18}$ Dari prioritas masalah tersebut dicari beberpa akar masalahnya dengan diagram fishbonedan diperingkat dengan metode CARL. Hasilnya, akar masalah yang prioritas adalah prosedur belum urut (obat disiapkan tanpa melihat permintaan di hari yang sama). Sehingga rekomendasi penyelesaiannya dilakukan dengan cara yaitu evaluasi ulang prosedur penyiapan dan distribusi obat UDD.

Implementasi manajemen lean yang dilakukan secara berturut turut adalah FGD penyusunan langkah prosedur distribusi UDD dan pembagian tugas dengan menggunakan data beban kerja, sosialisasi hasil dan prosedur yang telah disepakati dan disetujui direktur, uji coba pelaksanaan UDD dengan prosedur baru, lakukan evaluasi pelaksanaan dan analisa kekurangan dan kendala yang muncul. ${ }^{13,20}$ Pada tahap ini implementasi tidak bisa dilakukan secara maksimal dikarenakan melibatkan jajaran pelayanan medis yakni dokter penanggung jawab pasien dan keperawatan sehingga membutuhkan waktu yang lebih lama. ${ }^{14,17}$

Implementasi hanya sebatas pembuatan SPO baru mengenai penyimpanan obat dan alat kesehatan. Hal dikarenakan penyusunan kebijakan yang memerlukan pertemuan berkala dengan jajaran pelayanan sementara waktu penelitian yang terbatas membuat implementasi tidak bisa dilakukan dengan intervensi. Namun demikian bila SOP baru dijalanakan harapannya adalah (1) tidak adanya obat yang dikembalikan saat SPO baru diterapkan dan (2) pasien bisa pulang pada saat jam yang diperbolehkan pulang melalui kebijakan pasien pulang.

\section{KESIMPULAN}

Kesimpulan yang diperoleh adalah implementasi manajemen lean di unit farmasi RS Islam Surabaya A Yani dapat dilakukan mulai tahap perencanaan, pengadaan dan pembelian, penyimpanan, penyiapan serta distribusi dan pengembalian telah memberikan hasil yang lebih efisien diantaranya adalah mengurangi pembelian obat regular dan cito, mengurangi insiden ketidaktepatan pengiriman obat dengan purchase order, mengurangi stok meluber dan insiden stok obat tanpa label, mengurangi waktu tunggu obat jadi dan (mengurangi pengembalian obat dari ruangan.

\section{UCAPAN TERIMA KASIH}

Peneliti mengucapkan terima kasih kepada RS Islam Surabaya A. yani yang telah memberikan kesempatan untuk melakukan penelitian ini.

\section{DAFTAR PUSTAKA}

1. Aditama T.Y. Manajemen Administrasi Rumah Sakit. Universitas Indonesia, Jakarta. 2003.

2. Adrian N. A Lean Transformation, Quality Progress. February Vol. 44, No. 2; pp. 40. 2011.

3. Depkes RI. Standar pelayanan farmasi di rumah sakit. Direktorat Jenderal Bina Kefarmasian dan Alat Kesehatan. Jakarta. 2004.

4. Dickson E., Singh S., Cheung D., Wyatt C. \& Nugent A. Application of Lean manufacturing techniques in the emrgency departement. The Journal of Emergency Medicine. Vol. 37, pp. 177-182. 2009.

5. Forcelini. Value Stream Mapping: a study about the problems and challenges found in the literature from the past 15 years about application of Lean tools. International Journal of Advanced Manufacturing Technology 72(5-8):779-790 • May 2014

6. Dwiprahasto I. Idvokasi 
Draft Buletin Infarkes. Edisi V. Jakarta. 2014.

7. Dwi P. Pengembangan Indikator Efisiensi Pengelolaan Obat Di Farmasi Rumah Sakit. LOGIKA Vol. 3 No. 1 Januari. ISSN: 1410-2315. 2006.

8. Womack, J.P \& Jones, D.T. 1996. Lean Thingking: Banish Waste and Create Wealth in Your Corporation. New York: Simon \& Scuster

9. Herjunianto. Faktor yang Mempengaruhi Cakupan Layanan Farmasi di Instalasi Rawat Jalan Rumah Sakit. Jurnal Kedokteran Brawijaya. Vol 28, No. 1. Hal 8-13. 2014.

10. Infarkes. Jaminan Kesehatan dan Ketersediaan Obat. Edisi II MaretMei. Jakarta. 2015.

11. Jimmerson. Value Stream Mapping For Healthcare Made Easy. New York: Crc Press. 2010.

12. Keputusan Menteri Kesehatan Nomor 129/Menkes/SK/II/2008 tentang Standar Minimal Pelayanan Rumah Sakit. Jakarta. 2008.

13. McCullock Peter, Kreckler Simon, New Steve, Sheena Tezen, Handa Ashok, dan Catchpole Ken. Effect of "Lean" intervention to improve safety processes and outcome on a surgical emergency unit. British Medical Journal Vol. 341 pp. 5469. 2010.

14. Mellen R.C. dan Pudjirahardjo W.J, Faktor Penyebab Kerugian Akibat Stockout dan Stagnant Obat di Unit Logistik Rumah sakit Umum Haji Surabaya. Jurnal Administrasi Kesehatan Indonesia 1(1): 99- 107. 2013.

15. Sheina B., Umam M.R. dan Solikhah. Penyimpanan Obat di Gudang Instalasi Farmasi Rumah Sakit PKU Muhammadiyah Yogyakarta Unit I. Jurnal Kesehatan Masyarakat 4(1): 29-31. 2010.

16. Thompson, L., 2000. Making A Team : A Guide for Managers, Pearson. Pearson Prentice Hall, 2004, pp. 321.
17. Timperley, H. \& Robinson, V., 2000. The Power of Feedback Workload and the Professional Culture of Teachers. Research Article Educational Management Administration \& Leadership Early Career Reseacher, 1(12), pp. $200-223$.

18. Villiers., R. d., 2013. Seven Principles of highly effective managerial feedback: Theory and practice in managerial development interventions,. The International Journal of Management Education, Issue 11, pp. 66-74..

19. Vincent, C., 2003. Understanding and Responding to Adverse Event. The New England Journal of Medicine, 11(348), pp. 1051-1056..

20. Wakefield, J. G. \& Jorm, C. M., 2009. Patient Safety-a balanced measurement 